\title{
Identification of mechanisms involved in the relaxation of rabbit cavernous smooth muscle by a new nitric oxide donor ruthenium compound
}

João Batista Gadelha de Cerqueira, Lúcio Flávio Gonzaga-Silva, Francisco Ordelei Nascimento da Silva, João Victor Medeiros de Cerqueira, Ricardo Reges Maia Oliveira, Maria Elisabete Amaral de Moraes, Nilberto Robson Falcão do Nascimento

Departamento de Cirurgia (JBGC, LFGS, RRMO), Departamento de Química Orgânica e Inorgânica (FONS), Departamento de Fisiologia e Farmacologia (MEAM) Universidade Federal do Ceará, Ceará, Brazil and Instituto Superior de Ciências Biomédicas- Universidade Estadual do Ceará (JVMC, NRFN), Ceará, Brazil

\section{ABSTRACT}

Purpose: The aim of this study was to evaluate the relaxation in vitro of cavernous smooth muscle induced by a new NO donor of the complex nitrosil-ruthenium, named trans-[Ru(NH3) ${ }_{4}$ (caffeine)(NO) $] \mathrm{C}_{13}$ (Rut-Caf) and sodium nitroprusside (SNP).

Materials and Methods: The tissues, immersed in isolated bath systems, were pre-contracted with phenilephrine (PE) $(1 \mu \mathrm{M})$ and then concentration-response curves $\left(10^{-12}\right.$ - $10^{-4} \mathrm{M}$ ) were obtained. To clarify the mechanism of action involved, it was added to the baths ODQ $(10 \mu \mathrm{M}, 30 \mu \mathrm{M})$, oxyhemoglobin $(10 \mu \mathrm{M})$, L-cysteine $(100 \mu \mathrm{M})$, hydroxicobalamine $(100 \mu \mathrm{M})$, glibenclamide, iberotoxin and apamine. Tissue samples were frozen in liquid nitrogen to measure the amount of cGMP and cAMP produced.

Results: The substances provoked significant relaxation of the cavernous smooth muscle. Both Rut-Caf and SNP determined dose-dependent relaxation with similar potency $\left(\mathrm{pEC}_{50}\right)$ and maximum effect $\left(\mathrm{E}_{\max }\right)$. The substances showed activity through activation of the soluble guanylyl cyclase (sGC), because the relaxations were inhibited by ODQ. Oxyhemoglobin significantly diminished the relaxation effect of the substances. L-cysteine failed to modify the relaxations caused by the agents. Hydroxicobalamine significantly diminished the relaxation effect of Rut-Caf. Glibenclamide significantly increased the efficacy of Rut-Caf ( $\left.\mathrm{pEC}_{50} 4.09 \times 7.09\right)$. There were no alterations of potency or maximum effect of the substances with the addition of the other ion channel blockers. Rut-Caf induced production of significant amounts of cGMP and cAMP during the relaxation process.

Conclusions: In conclusion, Rut-Caf causes relaxation of smooth muscle of corpus cavernosum by means of activation of SGC with intracellular production of cGMP and cAMP; and also by release of NO in the intracellular environment. Rut-Caf releases the NO free radical and it does not act directly on the potassium ion channels.
ARTICLE INFO

\section{Key words:}

Nitric oxide; Nitrosyl-ruthenium complex; Endothelium, Vascular; Potassium Channel

Int Braz J Urol. 2012; 38: 687-94

Submitted for publication:

March 08, 2012

Accepted after revision:

July 27,2012

\section{INTRODUCTION}

Human corpus cavernosum contains vascular smooth muscle, kept under tonic contrac- tion induced by adrenergic excitation to maintain penile flaccidity (1). Nitric oxide (NO), the endothelium-derived relaxation factor discovered by Palmer and Moncada, is the main inhibitory neu- 
rotransmitter that mediates penile erection in all animals (2). NO activates soluble guanylate cyclase (sGC), which induces production of cyclic guanosine monophosphate (cGMP) from guanosine triphosphate (GTP). The cGMP acts in intracellular effectors, like protein kinase G (PKG), which cause diminishment of intracellular calcium and disassociation of actin and myosin fibers, ultimately leading to relaxation of the smooth muscle (2).

NO donors are substances that release NO, either in vivo or in vitro. One of these donors, sodium nitroprusside (SNP), is a powerful vasodilator utilized in patients with hypertensive crisis. Nevertheless, it is extremely labile, induces tolerance and releases cyanide, which is toxic to the endothelium (3).

NO is a potent vasodilator synthesized by neurons, endothelial cells, leucocytes and platelets among others. It is released by the autonomous nerve terminals, and by the vascular and sinusoidal endothelium when stimulated by acetylcholine (4).

Synthesis of NO is catalyzed by NOS, which converts l-arginine and oxygen to l-citruline and NO. NOS exists as three isoforms in mammals: nNOS and eNOS are preferentially expressed in neurons and endothelial cells, respectively, and iNOS in virtually all cell types. All three NOS isoforms have been identified in the corpus cavernosum, with nNOS and eNOS being considered responsible for initiating and sustaining erection, respectively (5). Down-regulation of nNOS expression has been found in the corpus cavernosum of aging rats (6), a model in which corpus cavernous smooth muscle relaxation is impaired (7).

Endothelial dysfunction is present in a large group of patients with erectile dysfunction (ED) and co-morbidities like hypertension and diabetes. This syndrome is characterized by an endogenous NO production deficiency (8). About $56 \%$ of patients in this group show resistance to current ED treatment with phosphodiesterase 5 (PDE-5) inhibitors (9). Research for new drugs that increase bioavailability of endogenous NO is a permanent challenge.

Recently, new NO donor compounds with higher stability and less toxicity have been subject of research. One group of such substances, S-nitroso-glutathione (GSNO) and S-nitroso-N- acetylcysteine-etylester (SNACET), was utilized in studies with strips of human corpus cavernosum mounted in isolated bath systems, proving to be potentially useful for tissue relaxation (10).

SNP has already been utilized intracavernously in vivo, in both human and animals, to induce penile erection. In dogs and monkeys, SNP induced dose-related erection, without causing hypotension (11). In patients with ED, SNP provoked erection of shorter duration than did papaverine, without side effects - like hypotension, injection site pain, or priapism $(11,12)$.

Ruthenium compounds, which are NO donors, have been tested in vitro and showed a similar relaxation to SNP on rat aorta smooth muscle (13). These compounds theoretically have the potential to be better than SNP because they do not release cyanide nor they react with the superoxide anion, forming peroxynitrite. However, further experimental studies are necessary to confirm this theory. Furthermore, they are stable at physiologic $\mathrm{pH}$ and soluble in water (13).

The aim of this study was to evaluated the relaxation in vitro of cavernous smooth muscle induced by a new NO donor of the complex nitrosyl-ruthenium, named trans-[Ru(NH3)4(caffeine) (NO)]C13 (Rut-Caf) and sodium nitroprusside (SNP).

\section{MATERIALS AND METHODS}

The study was approved by the local Committee of Ethics on Animal Use in Research. Adult male New Zealand rabbits, weight $2-3 \mathrm{~kg}$, were used. After anesthesia, the penis was removed entirely, and placed in Krebs-Henseleit solution. Cavernous tissue was dissected free of connective tissue and albuginea, providing two corpus cavernosum strips $(1 \mathrm{~cm})$ from each penis.

These strips were mounted in isolated baths (10 mL) containing Krebs-Henseleit solution. This solution contains $\mathrm{Na}, \mathrm{K}, \mathrm{Cl}, \mathrm{Ca}, \mathrm{MgSO} 4, \mathrm{HCO}$, P04, glucose, albumin, and tromethamine (THAM) and was used to maintain tissues during experiments (14). The strips were aired with a mixture of $\mathrm{O}_{2}(95 \%)$ and $\mathrm{CO}_{2}(5 \%), \mathrm{pH} 7.4,37^{\circ} \mathrm{C}$. Tissues were placed vertically, with tension of $1 \mathrm{~g}$. One extremity was connected to an isometric power 
transducer, while the other end was attached to a mobile unit that allowed tension adjustment.

The tissues rested for one hour. Tension was calibrated and the solution renewed every 15 minutes. Alterations on tension were registered on a polygraph (Gemini 7070, Ugo-Basile, Italy). Eight different experimental protocols were performed, as outlined next.

Experiment 1: After pre-contraction with phenilephrine $(1 \mu \mathrm{M})$, rising concentrations $\left(10^{-12}\right.$ - $10^{-3} \mathrm{M}$ ) of SNP (as a control) and Rut-Caf were administered to the baths and relaxation concentration-response curves were obtained.

Experiment 2: To evaluate the NO liberation profile for Rut-Caf, oxyhemoglobin $(10 \mu \mathrm{M})$ was added to the baths, 30 minutes before precontraction with phenilephrine $(1 \mu \mathrm{M})$.

Experiment 3: To evaluate possible anion nitroxyl (NO-) liberation by Rut-Caf during the relaxation process, L-cysteine $(100 \mu \mathrm{M})$, a specific NO- remover was added to the baths, 30 minutes before pre-contraction with phenilephrine $(1 \mu \mathrm{M})$.

Experiment 4: To evaluate the contribution of metabolically activated potassium channels $\left(\mathrm{K}_{\mathrm{ATP}}\right)$ on the relaxation process, one $\mathrm{K}_{\mathrm{ATP}}$ blocker - glibenclamide $(1 \mu \mathrm{M})$ - was added to the baths, 30 minutes before pre-contraction with phenilephrine $(1 \mu \mathrm{M})$.

Experiment 5: To evaluate the contribution of high, medium and low conductivity calcium-activated potassium channels $\left(\mathrm{K}_{\mathrm{CA}}\right)$ on the relaxation, two $\mathrm{K}_{\mathrm{CA}}$ blockers - iberotoxin $(1 \mu \mathrm{M})$ and apamine $(0.1 \mu \mathrm{M})$ - were added to the baths, 30 minutes before pre-contraction with phenilephrine $(1 \mu \mathrm{M})$.

Experiment 6: To evaluate the way NO is involved in the relaxation, hydroxocobalamin (0.1 $\mathrm{mM}$ ), a NO remover, was added to the baths, 30 minutes before pre-contraction with phenilephrine $(1 \mu \mathrm{M})$.

Experiment 7: To determine the activation of sGC by Rut-Caf, the agent $1 \mathrm{H}-[1,2,4]$ oxadiazole[4,3- $\alpha$ ]quinoxalin-1-one (ODQ) - a sGC blocker - was added to the baths, 30 minutes before pre-contraction with phenilephrine $(1 \mu \mathrm{M})$.

In all the experiments, relaxation concentration-response curves were obtained according to rising concentrations $\left(10^{-12}-10^{-3} \mathrm{M}\right)$ of Rut-Caf.
Experiment 8: The RbCC strips were frozen in liquid nitrogen for dosage of cGMP and cAMP. The method of non-acetylation was utilized and samples were separated for dosage of proteins according to the Bradford method (1976) (15). Trichloroacetic acid (TCA) was added to the tissue macerate, resulting in a final TCA concentration of $10 \%$. After centrifugation, the supernatant was washed with water saturated diethylic ether. This process was repeated six times. After the washings, the samples were dried in a nitrogen atmosphere at $60^{\circ} \mathrm{C}$, and then suspended again in the assay buffer of the immunoenzymatic kit for dosage of cGMP and cAMP.

The relaxant effect of the substances was measured from the maximal contraction plateau induced by phenilephrine, and expressed as percentages of contraction diminishment. The maximal effect $\left(\mathrm{E}_{\max }\right)$ was considered as the maximal amplitude response induced by the relaxant agents on the concentration-response curves. The drug concentrations that induced 50\% maximal relaxation $\left(\mathrm{pEC}_{50}\right)$ were determined after logarithmic transformation of concentration-response normal curves, and expressed as the negative logarithmic of values for each tissue $\left(\mathrm{pEC}_{0}\right)$. Percentages of contraction diminishment superior to $50 \%$ were considered significant.

The data were expressed as averages \pm standard deviation. Statistical analysis was performed with ANOVA, followed by the Tukey-Kramer test. Values of $p<0.05$ were considered significant.

\section{RESULTS}

The SNP Emax value was 100\%, and its pEC50 was $6.9 \pm 0.2$. For Rut-Caf, Emax value was $72.6 \pm 6.6 \%$, and $\mathrm{pEC}_{50}$ was $6.8 \pm 0.2$. There was no significant difference in potency between the two substances $(\mathrm{p}=0.851)$.

The relaxation curve induced by Rut-Caf was dislocated below with oxyhemoglobin, while the maximal response for Rut-Caf, in this setting, was $49.8 \pm 6.5 \%$.

Incubation of tissues with L-cysteine did not provoke any relaxation alterations. The values of pEC50 for Rut-Caf and Rut-Caf + L-cysteine were respectively $6.8 \pm 0.2$ and $6.9 \pm 0.2(\mathrm{p}=$ 
0.915). The $\mathrm{E}_{\max }$ value for Rut-Caf was $77 \%$ and for Rut-Caf + L-cysteine was 80\% (Figure-1).

Glibenclamide modified potency and efficacy of Rut-Caf, as reflected by $\mathrm{pEC}_{50}$ values for Rut-Caf of $5.2 \pm 0.2$ and Rut-Caf + glibenclamide of $7.3 \pm 0.2(\mathrm{p}=0.016) . \mathrm{E}_{\max }$ value increased from $68 \pm 8.9 \%$ to $92 \pm 7 \%(\mathrm{p}=0.060)$.

Tissue incubation with ibero-apamin did not interfere with Rut-Caf relaxations. The pEC50 for Rut-Caf was $4.7 \pm 0.2$, compared to $4.8 \pm 0.3$ for Rut-Caf + ibero-apamin ( $p=0.779$ ) (Figure-2).

Hydroxocobalamin almost abolished the relaxant effects of Rut-Caf. The pEC50 for Rut-Caf was $4.9 \pm 0.1$, while pEC50 for Rut-Caf + hydroxo- mg. Rut-Caf generated $143.52 \mathrm{pmoL} / \mathrm{mg}(\mathrm{p}<0.01)$ and SNP $43.50 \mathrm{pmoL} / \mathrm{mg}(\mathrm{p}<0.05)$ (Figure-4).

Finally, Rut-Caf $(100 \mu \mathrm{M})$ produced cAMP in the corpus cavernosum in quantity similar to that of forskolin $(10 \mu \mathrm{M})$ and significantly superior to the control amount ( $<<0.001)$ (Figure-5).

\section{DISCUSSION}

This study evaluated a new ruthenium compound and its capability to promote relaxation of cavernous smooth muscle.

The substance Rut-Caf provoked significant relaxation of cavernous smooth muscle

Figure 1 - Effect of Rut-Caf upon rabbit corpus cavernosum strips with and without pretreatment with $10 \mu \mathrm{M} / \mathrm{L}$ oxyhemoglobin, $1 \mathrm{mmoL} / \mathrm{L}$ L-cysteine or $0.1 \mathrm{mmoL} / \mathrm{L}$ hydroxocobalamin. Concentration/response curves were plotted for graded concentrations (10-12 to 10-3 M) of Rut-Caf. Results were expressed as average \pm standard error based on seven experiments. The statistical significance was verified with ANOVA followed by Buonferroni's test.

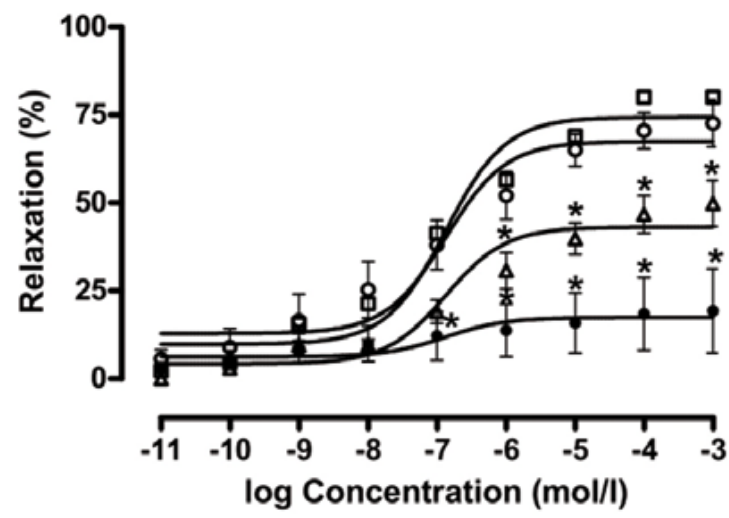

\author{
- Rut-Caf \\ $\triangle$ Rut-Caf+OxyHb \\ - Rut-Caf+L-Cys \\ - Rut-Caf+Hydroxycob
}

${ }^{*} \mathrm{p}<0.05$ vs. Rut-Caf without oxyhemoblin pretreatment.

${ }^{*} p<0.05$ vs. Rut-Caf without hydroxocobalamin pretreatment.

cobalamin was $5.5 \pm 0.2(\mathrm{p}=0.713)$. As to $\mathrm{E}_{\max }$, values were respectively $85.3 \pm 9.4 \%$ and $21.3 \pm$ $2.2 \%(\mathrm{p}<0.001)$.

The relaxation induced by Rut-Caf was significantly inhibited by ODQ. This is evidenced by the Emax values for Rut-Caf - $58 \pm 9.2 \%$ - and Rut-Caf + ODQ - $34.6 \pm 3.7 \%(p=0.038)$ (Figure-3).

Both SNP and Rut-Caf produced cGMP in the cavernous tissue in amounts significantly higher than the basal control value of $8.26 \mathrm{pmoL} /$
$($ Emax $=80 \%)$ with potency similar to SNP; however, with lower maximum effect. The most probable hypothesis is that SNP acts on relaxation of vascular smooth muscle activating the sGC and as a hyperpolarizing agent through direct activation of potassium ion channels and Rut-Caf acts mainly on activation of sGC (16).

The soluble isoform sGC plays a pivotal role in erectile function because it provides the link between NO and cGMP, which represent the 
Figure 2 - A. Relaxation induced by Rut-Caf in rabbit corpus cavernosum strips pre-contracted with $1 \mu \mathrm{M}$ phenylephrine with and without glibenclamide pretreatment. Results were expressed as average \pm standard error based on seven experiments. B. Relaxation induced by Rut-Caf in rabbit corpus cavernosum strips pre-contracted with $1 \mu \mathrm{M}$ phenylephrine with and without iberiotoxin/apamin pretreatment. Results were expressed as average \pm standard error based on seven experiments.

A
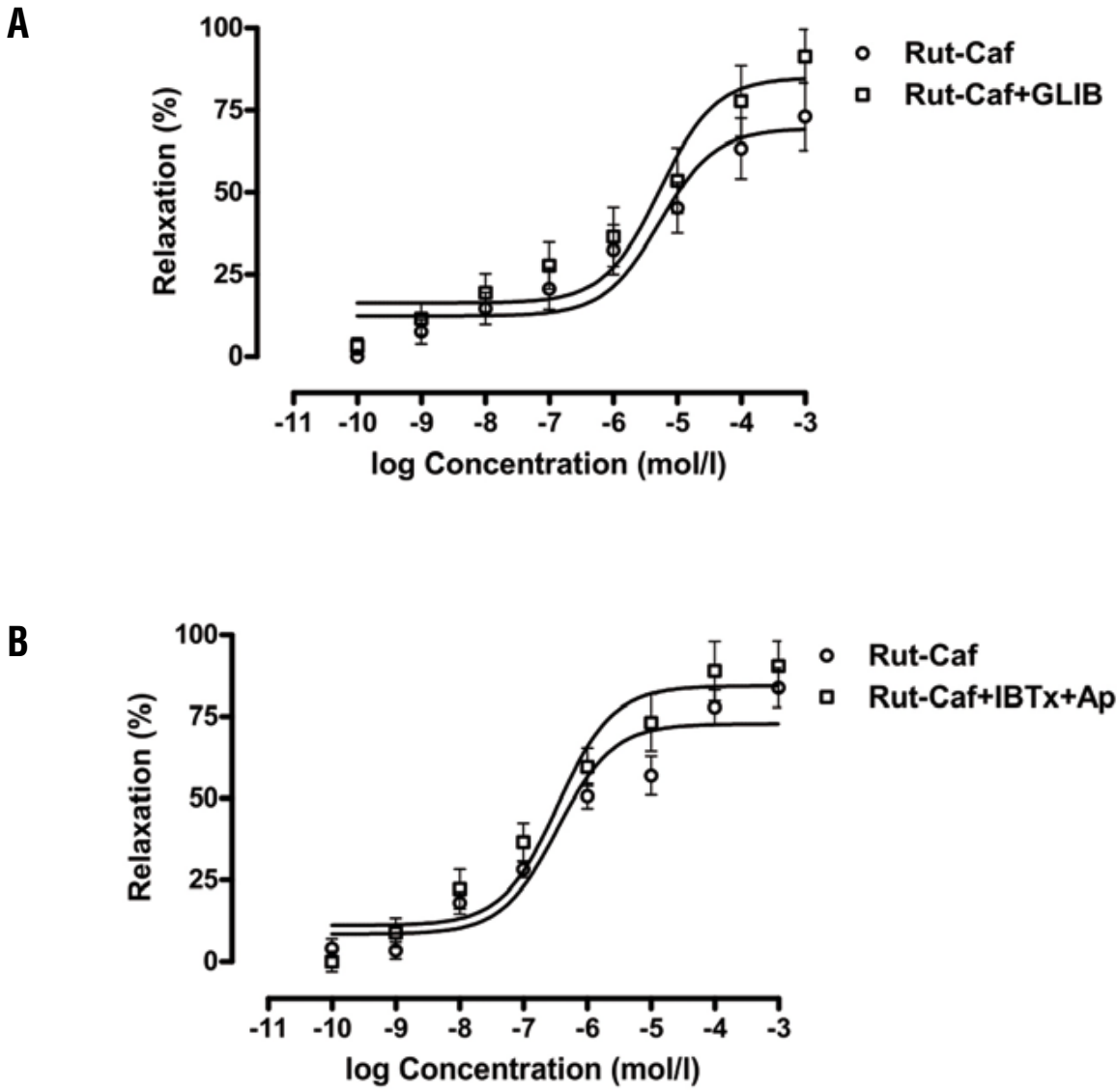

extracellular and intracellular signaling molecules, respectively, in physiologic erection (17).

Bonaventura et al., studying substances that also belong to the nitrosyl-ruthenium complex, in rabbit aorta rings, demonstrated a maximal relaxation effect of 102\% with pEC50 of 6.61 \pm 0.09 . These data confirm, as showed in this study, that ruthenium compounds are powerful vasodilators (13).

In vivo, NO arranges with hemoglobin creating a stable iron-nitrosyl complex that does not release NO. Bonaventura et al., evaluating the effects of ruthenium compounds in rabbit aorta rings in the presence of oxyhemoglobin, observed a decreased potency without significantly modif- ing its maximum effect, due to intracellular release of NO.

In this in vitro study, the addition of oxyhemoglobin to the organ baths reduced the maximum effect of Rut-Caf, but could not abolish it. Therefore, the relaxant effect of this substance is also probably due to the intracellular release of NO (13).

McDonald and Murad demonstrated that NO acts on the relaxation of vascular smooth muscle through activation of soluble guanylate cyclase, increasing the synthesis and bioavailability of intracellular cGMP (18). In this study, tissue incubation with a specific inhibitor of soluble guanylate cyclase (ODQ; $10 \mu \mathrm{M})$ abolished the re- 
Figure 3 - Concentration/response curves showing relaxation induced by Rut-Caf in rabbit corpus cavernosum strips with and without pre-treatment with $10 \mu \mathrm{M}$ ODQ or $30 \mu \mathrm{M}$ ODQ. Results were expressed as average \pm standard error based on seven experiments.

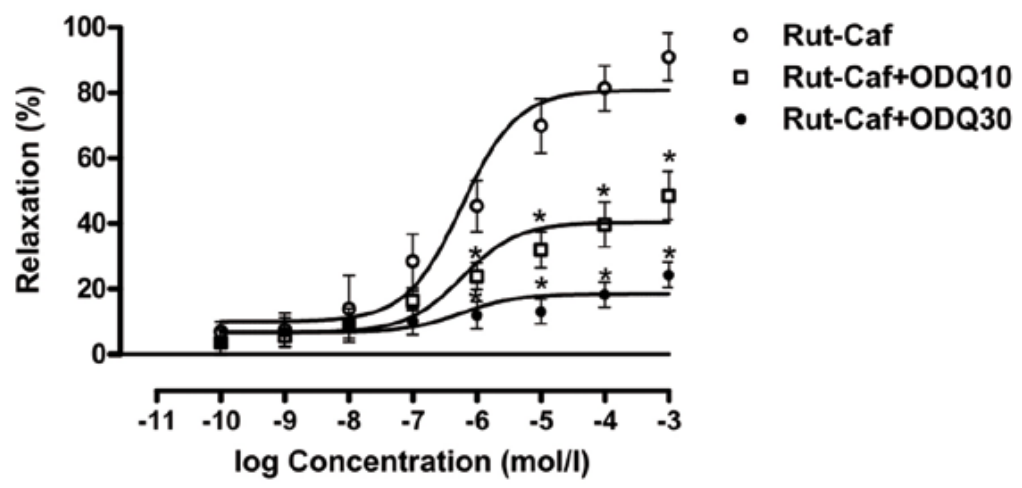

${ }^{*} \mathrm{p}<0.05$ vs. Rut-Caf with $10 \mu \mathrm{M}$ ODQ pretreatment

${ }^{*} p<0.01$ vs. Rut-Caf with $30 \mu \mathrm{M}$ ODQ pretreatment

Figure 4 - cGMP dosage of rabbit corpus cavernosum strips exposed to saline solution (control), $100 \mu \mathrm{M}$ Rut-Caf or 3 $\mu$ M SNP (positive control).

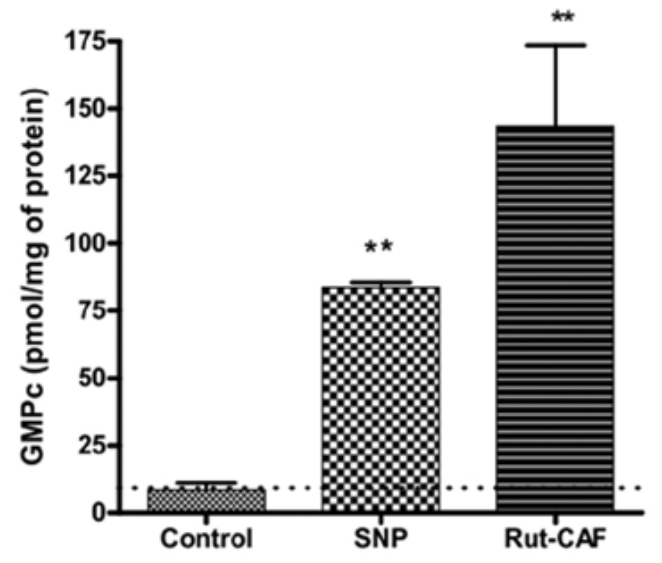

laxation response provoked by Rut-Caf. This demonstrates the action of the substance studied on the NO-cGMP cell signaling system.

According to the studies with compounds of the group nitrosyl-ruthenium, it was observed that these substances act by means of donation of free NO and nitroxyl anion (NO-) (13). Utilizing a specific nitroxyl anion remover, L-cysteine, the potential of relaxation remained unchanged. However, the addition of the NO free radical re-
Figure 5 - cAMP dosage of rabbit corpus cavernosum strips exposed to saline solution (control), $100 \mu \mathrm{M}$ Rut-Caf or 10 $\mu \mathrm{M}$ forscolin (positive control).

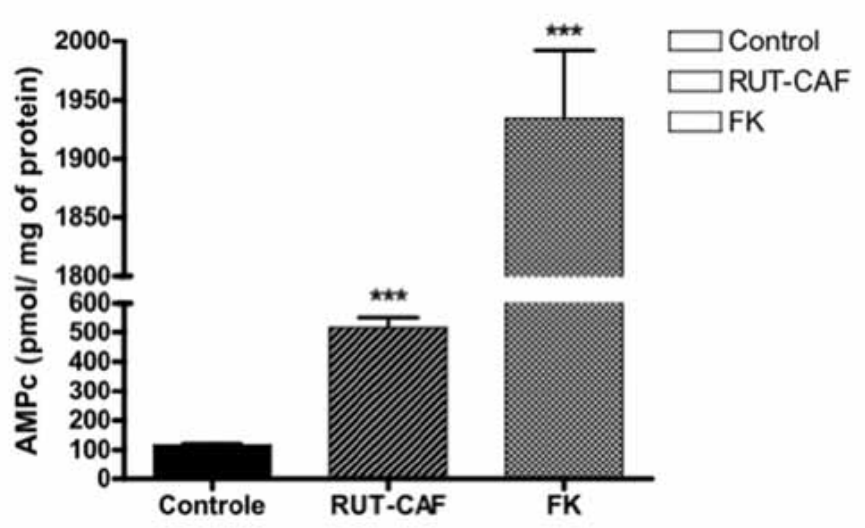

mover, hydroxocobalamin, to the baths significantly decreased the relaxation induced by RutCaf. In contrast with Bonaventura et al. findings, Rut-Caf does not release the nitroxyl anion during relaxation. In consequence, probably its relaxation effect is related to release of the NO free radical.

Smooth muscle has neither a T-tubule system nor a well-developed sarcoplasmatic reticulum. Therefore extracellular calcium plays an 
important role, and calcium must enter the cytoplasm through the plasma membrane during an action potential.

A direct hyperpolarizing action of the RutCaf was not observed. The addition of calcium activated potassium ion channels of high, medium and low conductivity inhibitors did not modify the relaxation effect of Rut-Caf. When glibenclamide, which is an ATP dependent potassium channel blocker, was added to the baths, an increase on the efficacy of Rut-Caf was observed (pEC50 4.04 $x$ 7.69, $p<0.05$ ).

The results obtained in this study were similar to the findings of Lee and Kang in human corpus cavernosum (19). These researchers, studying the effect of relaxation of a NO donor - SIN1 , could observe an increase in the probability of opening of calcium activated potassium channels in an indirect way, through activation of soluble guanylate cyclase and activation of the cGMP protein kinase. However, it was not demonstrated direct action of SIN-1 on the ion channels studied.

The best explanation for the efficacy of Rut-Caf would be the action of glibenclamide as a reducing agent. Bates et al. showed that the bioactivation of NO in biological medium needs the presence of a reducing agent. In consequence, glibenclamide acting as a reducing agent increase the efficacy of Rut-Caf (3).

This hypothesis was supported by the spectroscopic profile. The product formed (UVVis) is compatible with the formation of the species Rut-Caf- $\mathrm{H}_{2} \mathrm{O}$. Initially, there is a reduction of NO0 by glibenclamide with posterior liberation of the metal coordination sphere. In conclusion, this suggests that amplification in the presence of glibenclamide occurs due to reduction of $\mathrm{NO}+$ present in the metal coordination sphere, increasing the concentration of $\mathrm{NO}^{\circ}$ in the reactive environment.

Although it is known that ion channels effectively act on the control of the basal tone of the cavernous smooth muscle (1), they do not participate in the relaxation process induced by Rut-Caf.

The production of intracellular cGMP from activation of sGC by NO in different tissues was initially demonstrated by Arnold et al. (20). The production of cGMP in corpus cavernosum of animals and humans by NO donors, during the relaxation process, was demonstrated in studies $(10,21)$.

Similar to these studies, it was demonstrated that the production of cGMP induced by Rut-Caf in the relaxation of cavernous smooth muscle was significantly higher than that induced by saline solution and like that produced by SNP.

It was also observed production of cAMP induced by Rut-Caf during the relaxation process. Uckert et al. demonstrated the interaction of cGMP-cAMP cell signaling systems in the relaxation of cavernous smooth muscle (22). These authors demonstrated the presence of cAMP-specific phosphodiesterases, PDE- 3 and PDE- 5 in the cavernous endothelium. They also noted that the cAMP specific kinase PKA inhibited the relaxation induced by PDE-5 inhibitors, specific to cGMP, characterizing the integration of the cGMP-cAMP cell signaling systems on the cavernous smooth muscle relaxation. Although the mechanisms for that interaction are not clear, the authors have proposed that the increase in cAMP would be secondary to the drop in the level of cGMP, which would diminish the activity of PDE-3, increasing the level of cAMP. So, the regulation of cAMPspecific phosphodiesterases by cGMP could explain the increase of cAMP observed in this study, as a direct effect of Rut-Caf in the relaxation of cavernous smooth muscle.

Lindaman et al. studied the gallbladder smooth muscle in vitro. They noted that caffeine acting as an unspecific phosphodiesterases inhibitor 1 to 5 , increased the production of cGMP and cAMP in the relaxation process (23). Similarly, the presence of caffeine in the structure of Rut-Caf could contribute to the increase of cAMP produced by that substance.

It should be emphasized that the results of this study were obtained in in vitro experimental model and future studies in vivo and clinical studies are necessary in order to confirm them.

\section{CONCLUSIONS}

In conclusion, Rut-Caf causes relaxation of smooth muscle of corpus cavernosum by means of activation of sGC with intracellular production of cGMP and cAMP; and also by release of NO 
in the intra-cellular environment. Rut-Caf releases the NO free radical and it does not act directly on the potassium ion channels.

\section{CONFLICT OF INTEREST}

\section{None declared.}

\section{REFERENCES}

1. Andersson KE: Pharmacology of penile erection. Pharmacol Rev. 2001; 53: 417-50.

2. Lohse MJ, Förstermann U, Schmidt HH: Pharmacology of NO:cGMP signal transduction. Naunyn Schmiedebergs Arch Pharmacol. 1998; 358: 111-2.

3. Bates JN, Baker MT, Guerra R Jr, Harrison DG: Nitric oxide generation from nitroprusside by vascular tissue. Evidence that reduction of the nitroprusside anion and cyanide loss are required. Biochem Pharmacol. 1991; 42 (Suppl:) S15765.

4. Ignarro LJ: The unique role of nitric oxide as a signaling molecule in the cardiovascular system. Ital Heart J. 2000; 1 (Suppl 3): S28-9.

5. Hurt KJ, Musicki B, Palese MA, Crone JK, Becker RE, Moriarity $\mathrm{JL}$, et al.: Akt-dependent phosphorylation of endothelial nitric-oxide synthase mediates penile erection. Proc Natl Acad Sci U S A. 2002; 99: 4061-6.

6. Carrier S, Nagaraju P, Morgan DM, Baba K, Nunes L, Lue TF: Age decreases nitric oxide synthase-containing nerve fibers in the rat penis. J Urol. 1997; 157: 1088-92.

7. Cartledge J, Minhas S, Eardley I: The role of nitric oxide in penile erection. Expert Opin Pharmacother. 2001; 2: 95-107.

8. Feldman HA, Goldstein I, Hatzichristou DG, Krane RJ, McKinlay JB: Impotence and its medical and psychosocial correlates: results of the Massachusetts Male Aging Study. J Urol. 1994; 151: 54-61.

9. Rendell MS, Rajfer J, Wicker PA, Smith MD: Sildenafil for treatment of erectile dysfunction in men with diabetes: a randomized controlled trial. Sildenafil Diabetes Study Group. JAMA. 1999; 281: 421-6.

10. Seidler M, Uckert S, Waldkirch E, Stief CG, Oelke M, Tsikas $D$, et al.: In vitro effects of a novel class of nitric oxide (NO) donating compounds on isolated human erectile tissue. Eur Urol. 2002; 42: 523-8.

11. Trigo-Rocha F, Martinez-Piñeiro L, Donatucci CF, Hsu GL, Lue TF, Tanagho EA: Sodium nitroprusside: physiologic effects as a nitric oxide donor in three species. Int $\mathrm{J}$ Impot Res. 1995; 7: 49-56.
12. Shamloul R, Atteya A, Elnashaar A, Gadallah A, Zohdy W, Abdelsalam W: Intracavernous sodium nitroprusside (SNP) versus papaverine/phentolamine in erectile dysfunction: a comparative study of short-term efficacy and side-effects. J Sex Med. 2005; 2: 117-20.

13. Bonaventura D, de Lima RG, Vercesi JA, da Silva RS, Bendhack LM: Comparison of the mechanisms underlying the relaxation induced by two nitric oxide donors: sodium nitroprusside and a new ruthenium complex. Vascul Pharmacol. 2007; 46: 215-22.

14. Palea S, Barras M: Comparison of the relaxant effects of alfuzosin, phentolamine and sildenafil on rabbit isolated corpus cavernosum. BJU Int. 2003; 91: 873-7.

15. Bradford MM: A rapid and sensitive method for the quantitation of microgram quantities of protein utilizing the principle of protein-dye binding. Anal Biochem. 1976; 72: 248-54.

16. Bolotina VM, Najibi S, Palacino JJ, Pagano PJ, Cohen RA: Nitric oxide directly activates calcium-dependent potassium channels in vascular smooth muscle. Nature. 1994; 368: 850-3.

17. Andersson KE: Neurophysiology/pharmacology of erection. Int J Impot Res. 2001; 13 (Suppl 3): S8-S17.

18. McDonald LJ, Murad F: Nitric oxide and cyclic GMP signaling. Proc Soc Exp Biol Med. 1996; 211: 1-6.

19. Lee SW, Kang TM: Effects of nitric oxide on the Ca2+-activated potassium channels in smooth muscle cells of the human corpus cavernosum. Urol Res. 2001; 29: 359-65.

20. Arnold WP, Mittal CK, Katsuki S, Murad F: Nitric oxide activates guanylate cyclase and increases guanosine 3':5'-cyclic monophosphate levels in various tissue preparations. Proc Natl Acad Sci U S A. 1977; 74: 3203-7.

21. Kim NN, Huang YH, Goldstein I, Bischoff E, Traish AM: Inhibition of cyclic GMP hydrolysis in human corpus cavernosum smooth muscle cells by vardenafil, a novel, selective phosphodiesterase type 5 inhibitor. Life Sci. 2001; 69: 2249-56.

22. Uckert S, Hedlund P, Waldkirch E, Sohn M, Jonas U, Andersson KE, et al.: Interactions between CGMP- and CAMP-pathways are involved in the regulation of penile smooth muscle tone. World J Urol. 2004; 22: 261-6.

23. Lindaman BA, Hinkhouse MM, Conklin JL, Cullen JJ: The effect of phosphodiesterase inhibition on gallbladder motility in vitro. J Surg Res. 2002; 105: 102-8.

Correspondence address:

Dr. João Batista Gadelha de Cerqueira Rua Paula Ney, 599 /302, Aldeota Fortaleza, Ceará, 60140-200, Brazil E-mail: joaogadelhac@gmail.com 